\title{
PENGEMBANGAN DESAIN RUANG KELAS DALAM UPAYA MENDUKUNG TUMBUH KEMBANG ANAK USIA DINI
}

\author{
Refranisa ${ }^{1)}$, Chairul Saputra ${ }^{1)}$ \\ ${ }^{1)}$ Prodi Arsitektur, Institut Teknologi Indonesia, Tangerang Selatan, Banten \\ Corresponding author : Refranisa \\ E-mail : refranisa@iti.ac.id
}

\section{Diterima 22 Oktober 2020, Direvisi 30 Oktober 2020, Disetujui 31 Oktober 2020}

\begin{abstract}
ABSTRAK
Kegiatan ini merupakan kegiatan pengabdian pada masyarakat yang berlangsung karena adanya permintaan dari Ketua Pengurus PAUD Tunas Melati Malaka Jaya, Duren Sawit, Jakarta Timur . Pada kondisi sekarang ini keadaan PAUD Tunas Melati sebagai PAUD yang masih menggunkan bangunan RW sebagai wadah untuk pembelajaran. Para Pengurus mengusulkan untuk mengubah suasana ruang kelas dengan merenovasi ruang kelas agar lebih nyaman dan memberikan kesan menarik secara visual. Tujuan dari kegiatan ini adalah membantu para pengurus PAUD untuk melakukan renovasi pada ruang kelas, dengan membuatkan desain interior yang nantinya hasil desain tersebut dapat digunakan sebagai acuan pengembangan. Diharapkan dengan diadakanya desain ruang kelas dapat meningkatkan stimulus dan minat belajar pada siswa. Tahapan metode yang digunkan adalah dengan pengumpulan data, pembuatan desain lalu tahap evaluasi terhadap desain. Kegiatan pengabdian masyarakat ini dilakukan selama 3 bulan dimana kami melakukan diskusi konsep dan proses mendesainbersama dengan para pengurus PAUD Tunas Melati meliputi 7 orang guru dan 12 orang tua. Hasil Luaran yang dicapai pada kegiatan ini adalah desain ruang kelas yang digambar dalam bentuk 3D.
\end{abstract}

Kata kunci: desain ruang kelas;renovasi; anak usia dini.

ABSTRACT
This activity is a community service activity that takes place due to a request from the Chairperson of
the PAUD Tunas Melati Malaka Jaya Management, Duren Sawit, East Jakarta. In its current condition,
PAUD Tunas Melati still uses the RW building as a place for learning. The management proposes to
change the atmosphere of the classroom by renovating the classroom to make it more comfortable and
give a visually attractive impression. The purpose of this activity is to help PAUD administrators to make
renovations to classrooms, by making interior designs which later on can be used as a reference for
development. It is hoped that the holding of classroom design can increase the stimulus and interest in
learning in students. The stage of the method used is by collecting data, making the design and then
evaluating the design. This community service activity was carried out for 3 months where we discussed
the concept and design process together with the administrators of PAUD Tunas Melati, including 7
teachers and 12 parents. The output achieved in this activity is a classroom design that is drawn in 3D.

Keywords: classroom design; renovation; early childhood.

\section{PENDAHULUAN}

Pendidikan Anak Usia Dini (PAUD) merupakan peletak dasar pertama dan utama dalam pengembangan pribadi anak, baik berkaitan dengan karakter, kemampuan fisik, kognitif, bahasa, seni, sosial emosional, spiritual, disiplin diri, konsep diri, maupun kemandirian dan panca indra(Hakim, 2015). Pengembangan PAUD dikawasan kota Jakarta mendapat banyak sumber pendanaan dana dari instansi terkait diantaranya PAUD Tunas Melati Malaka Jaya, Jakarta Timur. PAUD Tunas Melati Malaka Jaya didirikan pada tahun
2016 dibawah naungan Kementerian Pendidikan dan Kebudayaan dengan nomor SK Operasional 6/1.17/31.75.05.1006/1.851.192/2017. Dilihat pada kondisi eksisting saat ini, bangunan PAUD Tunas Melati Malaka Jaya merupakan bangunan balai warga yang dialihfungsikan sebagai PAUD yang dikelola oleh warga sekitar oleh beberapa kader. Apabila dilihat dari segi visual, bangunan tersebut nampak seperti tipologi bangunan kantor dan kurang begitu menarik untuk digunakan sebagai bangunan pendidikan anak usia dini. 
PAUD didirikan sebagai suatu upaya pembinaan yang ditujukan kepada anak sejak lahir sampai dengan usia enam tahun yang dilakukan melalui pemberian rangsangan pendidikan untuk membantu pertumbuhan dan perkembangan jasmani dan rohani agar anak memiliki kesiapan dalam memasuki pendidikan lebih lanjut (PERMENDIKNAS No 58, 2009). Secara prosedur menurut Mendikbud 2019, hal terpenting dari konsep pendidikan usia dini adalah mengenalkan kepada anak-anak bagaimana belajar sambil bermain dimana dalam PAUD anak anak diarahkan agar mereka dapat berkolaborasi, menemukan kreativitas, kemudian menjadi cinta sekolah dan cinta belajar.

Anak membutuhkan rasa bebas, aman, nyaman, dan rangsangan untukmelakukan aktivitas di dalam ruang. Bebas artinya anakanak bisa leluasa, ber-aktivitas dan mengekspresikan kreativitas mereka di dalam sebuah ruang. Untuk itu,anak memerlukan ruang yang fleksibel, tidak terlalu padat, serta didukung dengan warna terang dan netral. Skema warna netral adalah yang paling fleksibel (Mayang, 2004). Keseluruhan desain untuk anak haruslah sebuah gabungan dari kreativitas, fungsi dan fleksibilitas. Ruangan tersebut harus mampu menstimulasi imaginasi mereka dan mewadahi berbagai perilaku anak(Olivia Renata Kuswandi, 2019). Kriteria ruangan anak mungkin dapat diringkas dengan sesuatu yang bersifat : mengundang, nyaman, aman, tahan lama, menarik (S K Feinberg, 2010).

Dengan adanya pembahasan tersebut, maka dibutuhkan sebuah ruang sarana pendidikan untuk anak usia dini dengan elemen-elemen interior yang dapat mencakup atau mengoptimalkan kecerdasan yang dimiliki pada pertumbuhan dan perkembangan anak dengan metode pembelajaran. Kegiatan ini merupakan kegiatan pengabdian pada masyarakat yang berlangsung untuk membantu membuat gambar desain ruang kelas PAUD Tunas Melati Malaka Jaya agar bangunan PAUD Tunas melati dapat menarik secara visual dari segi arsitektur bangunan. Melihat dari antusias pengurus yang ingin meningkatkan kualitas visual agar dapat meningkatkan suasana bermain sambil belajar bagi para murid, maka urgensi desain yang diusulkan adalah desain interior pada ruang belajar PAUD Tunas Melati Malaka Jaya. Desain interior bukan hanya merencanakan fasilitas dalam ruang, tetapi juga memberi nuansa ruang tersebut yang berdampak positif bagi penggunanya.(Anggra Ayu Rucitra, 2020)
Metode pelaksanaan dalam penyusunan laporan pengabdian masyarakat terdiri rangkaian beberapa kegiatan yaitu: pengumpulan data dan pembuatan konsep desain ruang kelas. , kemudian hasil dari desain dipresentasikan kepada mitra yaiu para pengurus PAUD Tunas Melati untuk mendapatkan masukan dan persetujuan Tahap pengumpulan data dilakukan langsung pada lokasi obyek desain yaitu ruang Kelas Paud Tunas Melati. Hasil desain dipresentasikan disalah satu rumah pengurus Paud Tunas Melati dan dihari oleh 19 peserta.

\section{Tahap pengumpulan data.}

Pada langkah ini kami melakukan pengamatan terhadap kondisi eksisting, perilaku pengguna dan aktivitas kegiatan yang dilakukan, sekaligus jenis-jenis perabot yang mendukung.

1. Kondisi Eksisting

Dilihat pada kondisi eksisting saat ini, seperti yang terlihat pada Gambar 1, bangunan PAUD Tunas Melati Malaka Jaya merupakan bangunan balai warga yang dialihfungsikan sebagai PAUD yang dikelola oleh warga sekitar oleh kaderisasinya.

- Lokasi JI. Taman Malaka Utara Blok B, Malaka Jaya, Kec. Duren Sawit, Kota Jakarta Timur Prov. D.K.I. Jakarta

- Luas desain ruang : $120 \mathrm{~m} 2$

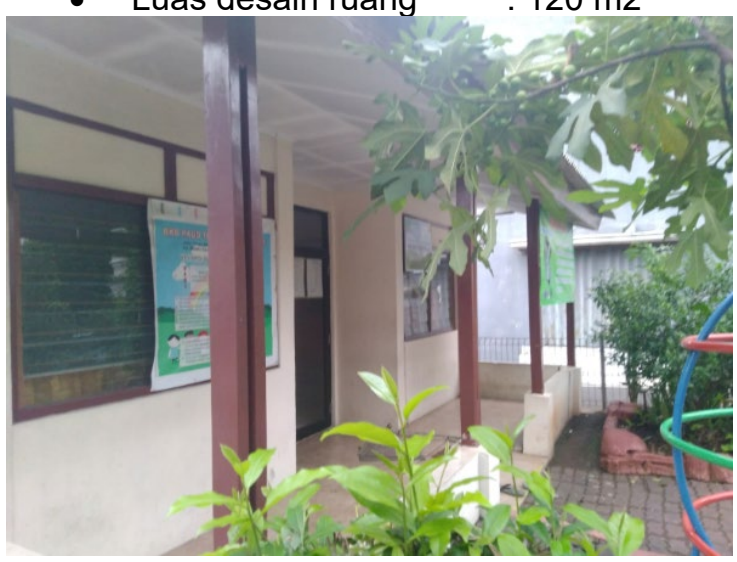

Gambar 1 : Kondisi Eksisting Depan Bangunan

(Sumber : Survey, 2020)

2. Identifikasi Pengguna

Adapun identifiksi terhadap pengguna ruang PAUD Tunas Melati Malaka Jaya dapat dilihat pada tebel 1 .

Tabel 1. Identifikasi Pengguna

\begin{tabular}{cc}
\hline Jenis Pengguna & Jumlah Pengguna \\
\hline Tenaga Pendidik & 7 orang \\
\hline Murid Laki - Laki & 15 orang \\
\hline Murid Perempuan & 15 orang \\
\hline
\end{tabular}

\section{METODE}


3. Jenis aktivitas

Kegiatan pembelajaran yang dilakukan pada PAUD Tunas Melati dapat dilihat pada Gambar 2. Adapun kegiatan yang dilakukan diantaranya adalah sebagai berikut :

- Belajar beribadah

- Mengenalkan angka dan huruf

- Mengambar dan mewarnai

- Bermaian balok dan puzzle

- Bernyanyi dan menari

- Makan bersama

- Kreasi seni (menghias, menggunting, menempel), dll

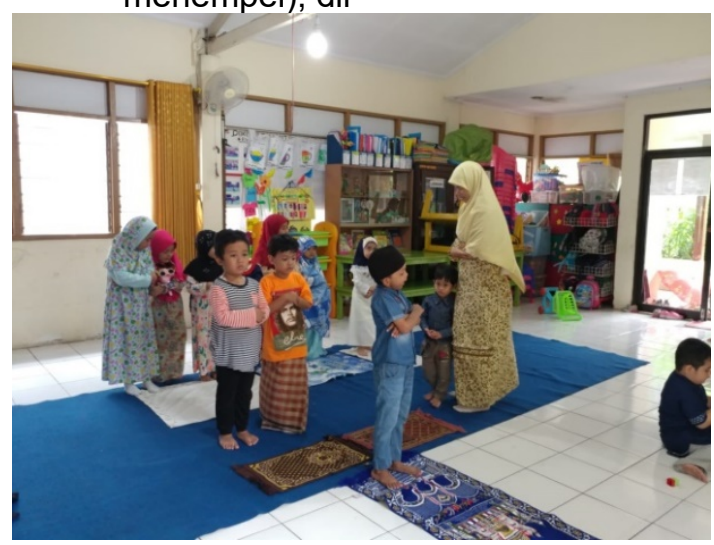

Gambar 2 : Kegiatan siswa didalam ruangan (Sumber : Survey, 2020)

4. Jenis perabot

Dilihat dari fungsinya, jenis perabot pada PAUD Tunas Melati Malaka Jaya dapat dikelompokkan menjadi:

- Perabot belajar anak, seperti : meja dan kursi anak, lemari atau rak penyimpanan alat bermain, loker anak, papan pajangan hasil karya anak, rak sepatu, gantungan tas, dll.

- Perabot penunjang kegiatan kelembagaan, seperti: meja dan kursi guru, meja dan kursi tamu, lemari guru, rak penyimpanan data anak, dll.

Contoh perabot yang tersedia di PAUD Tunas Melati dapat dilihat pada Gambar 3.

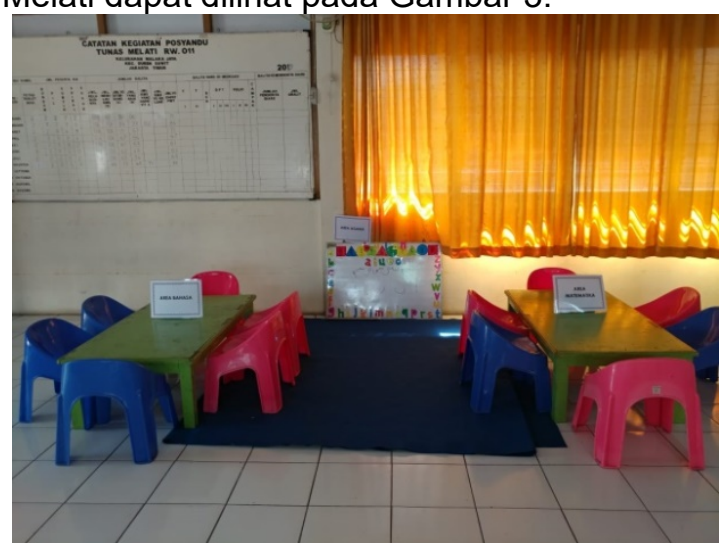

Gambar 3 : Kondisi Ruang Kelas

(Sumber : Survey, 2020)

\section{Tahap Konsep Desain Interior}

Konsep perancangan desain interior PAUD Tunas Melati Malaka Jaya adalah mengusung tema "Learn by doing with careful". Konsep ini bertujuan untuk menciptakan ruangan yang aman, nyaman, dan menyenangkan secara fisik, visual, ergonomi, maupun psikologi guna merangsang dan memberikan stimulus timbulnya minat anak dalam belajar dan eksplorasi, agar dapat memicu kreatifitas, memudahkan aktifitas, serta menunjang kebutuhan pengguna didalamnya namun tidak menimbulkan cidera bagi pengguna.

- Konsep Bentuk : Menggunakan bentuk yang dinamis dan geometris agar dapat memberikan kesan bebas saat beraktivitas

- Konsep Warna : Menggunakan warnawarna dasar yang dapat merangsang stimulus anak untuk semangat melakukan aktivitas. Penggunan warna yang tepat pada suatu ruang dapat memotivasi pengunyanya (Wichmann F, Sharpe L, 2012). Melalui warna juga dapat meningkatkan kemampuan untuk mengingat kata dan gambar (Judy, 2014).

- Konsep Material : Material yang diusulkan pada desain interior ini adalah menggunakan material yang aman dan tidak membahayakan bagi anak anak, seperti parquet, keramik, matras.

- Konsep Perabot : Usulan desain perabot seperti meja, dan kursi untuk belajar anak tidak memiliki sudut tajam, ergonomis dan tidak mencelakakan anak kecil saat melakukan aktivitas. Meja dibuat ergonomis dan tidak bertekstur karena akan membahayan pengguna serta dapat mengganggu belajar mengajar karena hasil dari tugas belajar tersebut tidak dapat maksimal (Jennie Hasimjaya, Mariana Wibowo, 2017).

\section{HASIL DAN PEMBAHASAN}

Hasil dan luaran pengabdian masyarakat yang dilakukan di PAUD Tunas Melati Malaka Jaya adalah berupa gambar desain 3D yang dicetak. Hasil luaran desain dapat dilihat pada Gambar 4 dan Gambar 5 berikut ini. 


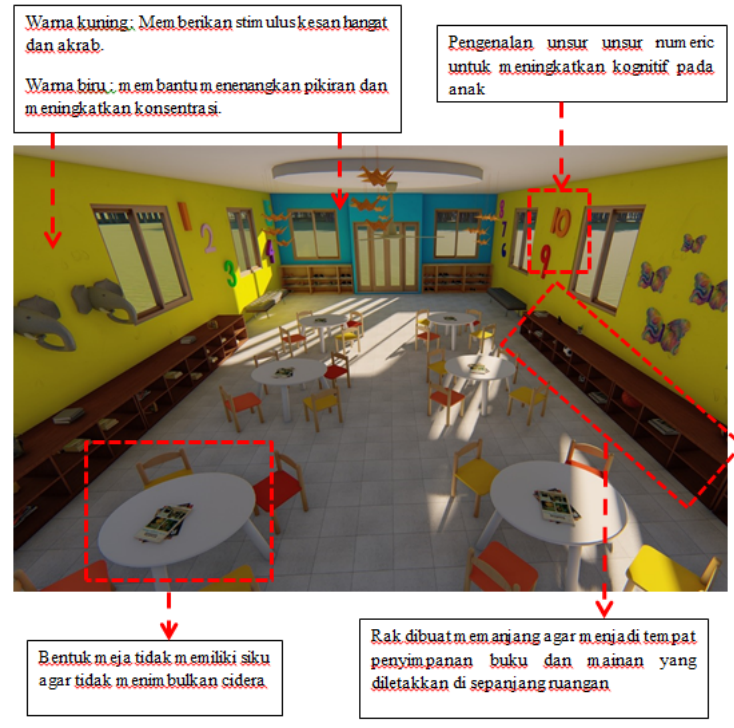

Gambar 4 : Detail perabot keseluruhan ruang (Sumber : Hasil Desain penulis, 2020)

Desain disesuaikan dengan tujuan stimulus yaitu menggunakan warna kuning untuk memberikan stimulus kesan hangat dan akrab. Warna biru membantu menenangkan pikiran dan meningkatkan konsentrasi(Majidah, Dian Hasfera, 2019). Serta penambahan Pengenalan unsur unsur numerik untuk meningkatkan kognitif pada anak. Warna biru dianggap warna dingin demikian juga efek yang akan diberikan kepada penggunanya adalah pengguna akan menganggap tempat itu lebih dingin daripada sebenarnya. Bentuk meja tidak memiliki siku agar tidak menimbulkan cidera. Rak dibuat memanjang agar menjadi tempat penyimpanan buku dan mainan yang diletakkan di sepanjang ruangan.

Sudut ruang difungsikan sebagai area baca dimana diletakan rak buku berbahan dasar kayu jati belanda agar material terkesan soft. Perabot kursi didesain secara ergonomi, berwarna dominan kuning dan orange. Bahan dudukan kursi terbuat dari matras.

Hasil desain yang dilakaukan dipaparkan pada malam hari dirumah salah satu pengurus Paud Tunas Melati yaitu ibu Sumiati, bersama dengan rekan rekan kader dan warga sekitar selaku orang tua murid. Desain dicetak berbentuk draft, lalu dilakukan evaluasi terhadap desain tersebut. Para hadirin cukup mengapresiasi atas desain yang ditawarkan sehingga untuk kedepanya desain yang sudah dibuat dapat dijadikan acuan sebagai pengembangan desain ruang kelas pada PAUD Tinas Melati kedepan.

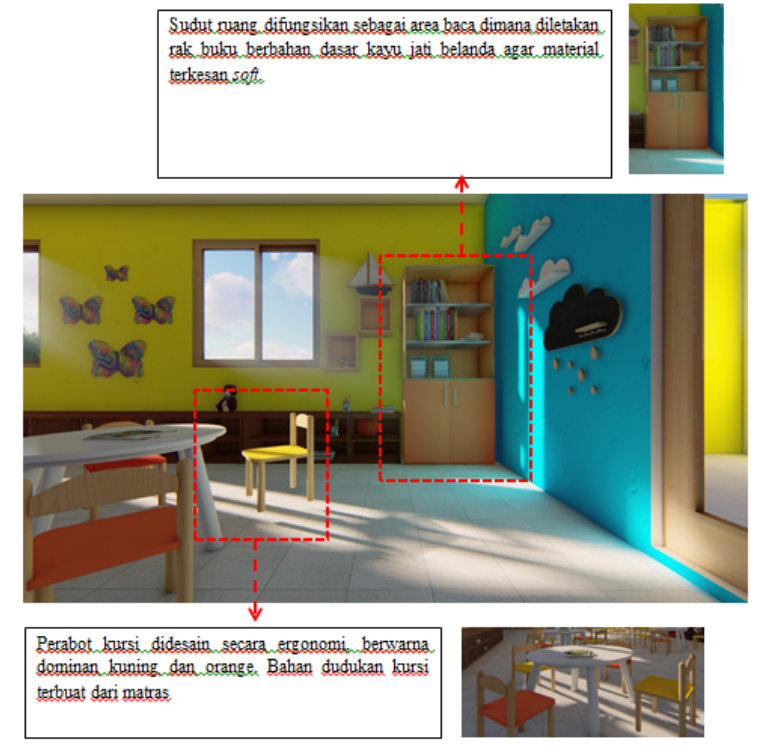

Gambar 5 : Detail perabot pada sudut ruang (Sumber : Hasil Desain penulis, 2020)

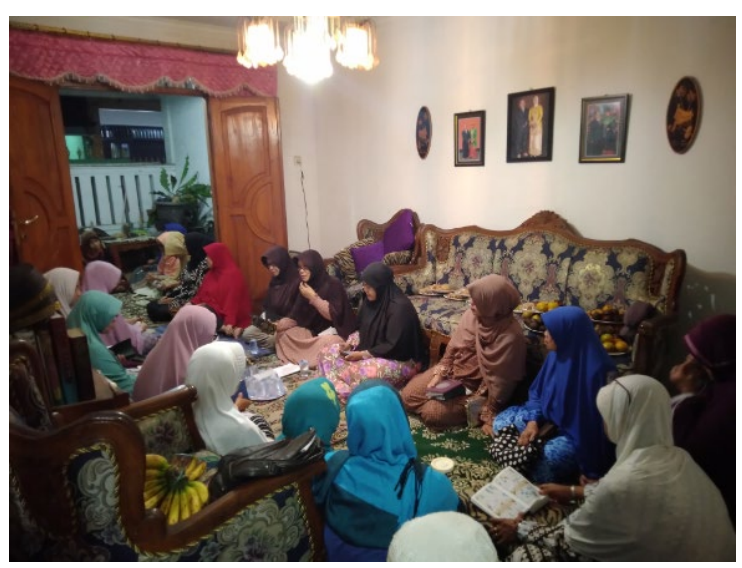

Gambar 6 : Pemaparan Hasil Desain

(Sumber : Dokumentasi pribadi, 2020)

\section{SIMPULAN DAN SARAN}

Pelaksanaan penyusunan laporan pengabdian masyarakat berjalan lancar meskipun target luaran yang telah diminta berupa gambar prarancangan yang ditampilkan secara visual 3D. Namun secara umum, pelaksanaan pengabdian masyarakat ini sudah sesuai dengan durasi yang ditentukan yaitu selama 3 bulan. Terlaksananya pengabdian masyarakat hingga terselesaikannya penyusunan laporan ini tidak lepas dari keterlibatan beberapa pihak khususnya Program Studi Arsitektur Institut Teknologi Indoensia. Semoga apa yang telah diusahakan dapat memberikan manfaat bagi kedua belah pihak, yaitu bagi PAUD Tunas Melati Malaka Jaya serta bagi Prodi Arsitektur Institut Teknologi Indonesia 


\section{DAFTAR RUJUKAN}

Anggra Ayu Rucitra (2020) 'Merumuskan Konsep Desain Interior', Jurnal Desain Interior, Vol. 5, No(pISSN 2527-2853, elSSN 2549-2985), pp. 31-44.

Hakim, S. (2015) 'Pendidikan Anak Usia Dini (PAUD) Dalam Perspektif Islam', Jurnal Lentera: Kajian Keagamaan, Keilmuan dan Teknologi, Volume 1,.

Jennie Hasimjaya, Mariana Wibowo, D. W. (2017) 'Kajian Antropometri \& Ergonomi Desain Mebel Pendidikan Anak Usia Dini 3-4 Tahun di Siwalankertole', Jurnal Intra, Volume 5 $\mathrm{N}$, pp. 449-459.

Judy (2014) The color of learning: enhance memory and retention with a splash of color.

Majidah, Dian Hasfera, M. F. (2019) 'Penggunan Warna dalam Desain Interior Perpustakaan terhadap Psikologis Pemustaka', Ristekdik (Jurnal Bimbingan dan Konseling), Vol 4, No., pp. 95-106.

Mayang, S. S. (2004) 'No Peran Warna Interior terhadap Perkembangan dan Pendidikan Anak di Taman KanakKanak', Jurnal Dimensi Interior, Volume 2 N, pp. 22-36.

Olivia Renata Kuswandi, M. W. (2019) 'KajianInterior PAUD dan Taman Bacaan Masyarakat diRuangMultifungsi diArea-Eks Lokalisasi Dolly Surabaya', Jurnal Intra, Volume $7 \mathrm{~N}$, pp. 551-564.

PERMENDIKNAS No 58 (2009) Standart Pendidikan Anak Usia Dini.

S K Feinberg (2010) Designing Space for Children and Teens in Libraries and Public places. Chicago: American Library Association.

Wichmann F, Sharpe L, \& G. K. (2012) 'The contributions of color to recognition memory for naturalscenes', Journal of Experimental Psychology, Volume 28, pp. 509-520. 